\title{
La otra fitoterapia en urología
}

\author{
E. Peyrí Rey \\ Unidad de Urología. Hospital Comarcal de la Selva Blanes. Girona
}

Actas Urol Esp 2005; 29 (7): 721

\begin{abstract}
Tos extractos de plantas en urología aparte de Los preparados por la industria farmacéutica, siguen usándose en pacientes que acuden a herboristerias, siendo mucho más frecuente la utilización de esta terapia en el medio rural. La fitoterapia en urologia se emplea sobre todo en el tratamiento de la patología prostática, litiásica y del área sexual. Las hierbas diuréticas siguen usándose en el tratamiento de la hipertensión arterial. Creo que la base de esta terapia con extractos vegetales la tendría que conocer el urólogo, más cuando muchos de estos enfermos que la utilizan, narran una mejoría de su sintomatología.
\end{abstract}

Dr. E. Peyrí Rey

Valencia $247,1^{\circ}-1^{\underline{a}}$

08007 Barcelona

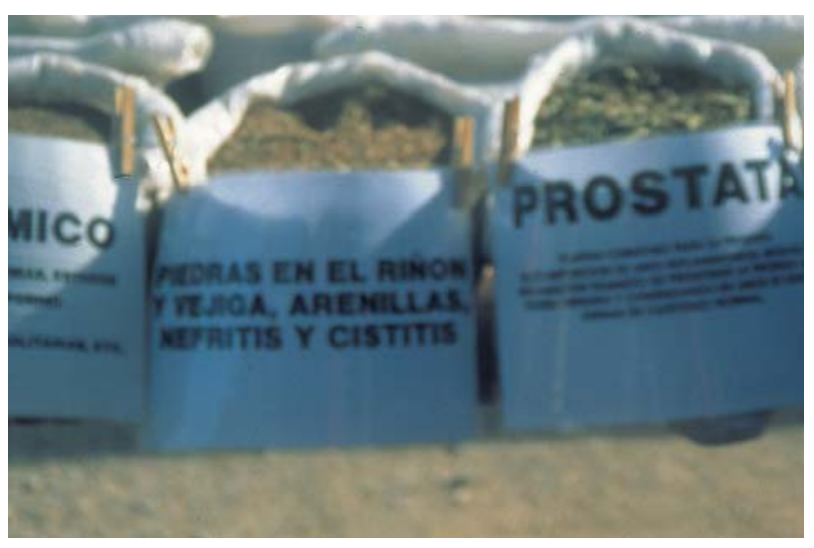

FIGURA 1 